\title{
Real-World Treatment Patterns and Outcomes Among Multiple Myeloma Patients with Asthma and COPD in the United States
}

\author{
Megan S. Rice $\cdot$ Sarah Naeger $\cdot$ Erin Singh
}

Received: January 26, 2021 / Accepted: February 26, 2021 / Published online: March 17, 2021

(C) The Author(s)

\begin{abstract}
Introduction: Multiple myeloma (MM) is the second most frequent hematologic malignancy after lymphoma, contributing to approximately $10 \%$ of all hematologic malignancies. The prognosis of patients with MM is impacted by the heterogeneity of the disease, with worse outcomes reported in patients classified as International Staging System stage III, those with high-risk cytogenetics and elevated serum lactate dehydrogenase, and among patients who are elderly and have comorbidities. Previous studies have demonstrated an association between the presence of lung disease and worse outcomes; however, this impact in a real-world setting is not well understood.

Methods: This retrospective, observational, cohort study included data from the nationwide US Optum ${ }^{\circledR}$ de-identified electronic health record (EHR) database from January 1, 2006, to December 31, 2019. MM patients with asthma or chronic obstructive pulmonary disease (COPD) were compared with $\mathrm{MM}$ patients without asthma or COPD for time to next treatment and overall survival using one-sided log-rank tests stratified by age and multivariable Cox proportional hazard models.
\end{abstract}

M. S. Rice $(\bowtie) \cdot$ S. Naeger · E. Singh

50 Binney Street, Cambridge, MA 02142, USA

e-mail: megan.rice@sanofi.com
Results: Among 5186 patients with MM, approximately $15 \%$ had an asthma or COPD diagnosis (asthma/COPD) at baseline. The most commonly observed comorbidities among all MM patients and among those MM patients with asthma/COPD were cardiovascular disease, diabetes, and renal impairment. Time from firstto second-line treatment was significantly longer for patients with a diagnosis of COPD. Overall survival from first-line therapy was significantly worse among patients with COPD, with numerically worse overall survival from second-line therapy.

Conclusion: These real-world data suggest that patients with asthma or COPD do not experience a shorter time interval to next treatment, but have significantly worse overall survival from start of first-line therapy and numerically worse survival from the start of later lines. Future investigations with larger datasets may improve the understanding of the influence of individual treatments on outcomes in these patients.

Keywords: Asthma; COPD; Multiple myeloma; Real-world evidence 


\section{Key Summary Points}

Why carry out this study?

Comorbidities are known to impact outcomes in patients with multiple myeloma, but many patients with pulmonary disease are excluded from clinical trials; therefore, not much is known about this subgroup of patients.

Previous results have demonstrated an association between the presence of lung disease and worse outcomes; however, this impact in a real-world setting is not well understood.

The objective of the current study was to assess the prevalence of asthma and chronic obstructive pulmonary disease (COPD) in a real-world patient population with multiple myeloma, and to describe treatment patterns in patients with/ without asthma/COPD, and time to next treatment and overall survival in patients with asthma/COPD.

\section{What was learned from the study?}

These real-world data suggest that patients with asthma or COPD experience prolonged time to next treatment from first to second line, but have significantly worse overall survival from start of firstline therapy and numerically worse survival from the start of later lines of therapy.

Future investigations with larger datasets may improve the understanding of the influence of individual treatments on outcomes in these patients.

\section{DIGITAL FEATURES}

This article is published with digital features, including a summary slide, to facilitate understanding of the article. To view digital features

for this article, go to https://doi.org/10.6084/ m9.figshare.14113682.

\section{INTRODUCTION}

Multiple myeloma (MM) is the second most frequent hematologic malignancy after lymphoma, contributing to $1 \%$ of all cancers and approximately $10 \%$ of all hematologic malignancies $[1,2]$. Despite the introduction of targeted therapies and combination regimens, patients with MM continue to experience multiple relapses and/or become refractory to treatment [3].

The prognosis of patients with MM has been shown to be impacted by the heterogeneity of the disease, with prognostic factors categorized by burden of disease, tumor biology, host factors, and depth of response to therapy [4]. Worse outcomes have been reported in patients classified as International Staging System stage III, those with high-risk cytogenetics and elevated serum lactate dehydrogenase, and among patients who are elderly and have comorbidities. Treatment decision-making may require consideration of preexisting comorbidities and organ dysfunction, which have been associated with an increased risk of treatment- and diseaserelated complications that contribute to high levels of mortality earlier in the treatment continuum.

In ICARIA-MM, a recent phase 3 study of isatuximab, an anti-CD38 monoclonal antibody that has been approved in combination with pomalidomide and dexamethasone in the United States, the European Union, Japan, and other countries for the treatment of adult patients with relapsed/refractory MM who have received at least two prior therapies, including lenalidomide and a proteasome inhibitor (PI) [5-9], approximately $10 \%$ of patients had a previous history of asthma or chronic obstructive pulmonary disorder (COPD) [10]. However, previous MM studies investigating other molecules have used COPD/pulmonary disease as an exclusion criterion (e.g., POLLUX; ELOQUENT2 [if uncontrolled]; CASTOR; CANDOR; MAIA; CASSIOPEIA) [11-16]. As a result, little is known from randomized controlled trials about 
treatment patterns and outcomes in $\mathrm{MM}$ patients with respiratory comorbidities. Although some retrospective studies have demonstrated an association between the presence of lung disease and worse outcome [17], and an independent association has been reported between pulmonary function abnormalities and worse outcome in patients with MM [18], the real-world impact of preexisting lung disease is not well understood.

Therefore, the objective of the current study was to assess the prevalence of asthma and COPD in a real-world patient population with $\mathrm{MM}$, and to describe treatment patterns, time to next treatment, and overall survival in $\mathrm{MM}$ patients by asthma/COPD status.

\section{METHODS}

This retrospective, observational, cohort study included data from the nationwide US Optum ${ }^{\circledR}$ de-identified electronic health record (EHR) database. The dataset includes all data collected from January 1, 2006, to December 31, 2019. The dataset is statistically deidentified under the Expert Determination method consistent with the Health Insurance Portability and Accountability Act and managed according to Optum's customer data use agreements. This article is based on previously collected data and does not contain any studies with human participants or animals performed by any of the authors.

\section{Inclusion Criteria}

Inclusion and exclusion criteria are described in Table 1. In this study, patients were included if they had $\geq 2$ medical records with a diagnosis of $\mathrm{MM}$ at least 30 days apart but no more than 365 days apart. The first of these two medical records was considered the diagnosis date. Patients were aged $\geq 18$ years as of the first observed treatment for MM. Patients had $\geq 1$ medical record for a medical service with a procedure code or a prescription for an MM treatment, including immunomodulatory drugs (i.e., thalidomide, lenalidomide, pomalidomide), proteasome inhibitors (PIs; i.e., bortezomib, carfilzomib, ixazomib), histone deacetylase inhibitors (i.e., panobinostat), monoclonal antibodies (i.e., daratumumab, elotuzumab, isatuximab), chemotherapy (i.e., bendamustine, cisplatin, cyclophosphamide, doxorubicin, etoposide, liposomal doxorubicin, melphalan), or other treatments (i.e., selinexor, an inhibitor of nuclear export). Patients were included if they initiated the first MM treatment $\leq 1$ month prior to or any time after the MM diagnosis date, and if they initiated firstline therapy for first observed treatment for MM on or after January 1, 2012. Patients were enrolled in an integrated delivery network and must have had at least one medical activity within 12 months prior to the index date (date of initiation of the line of therapy) and at least one medical activity within 2 months after the index date.

\section{Exclusion Criteria}

Patients were excluded if any of the following criteria were met: an indicator of enrollment in a clinical trial on or after the first observed treatment for $\mathrm{MM}, \geq 2$ medical records on different days with a diagnosis for a blood cancer other than MM at any time, $\geq 1$ medical record with a diagnosis for neoplasm of unspecified nature on or after the first observed treatment for $\mathrm{MM}, \geq 2$ medical records with a diagnosis for malignant neoplasm $\leq 2$ years prior to the first observed treatment for MM, an indicator of stem cell transplant (SCT) prior to the first observed treatment for $\mathrm{MM}, \geq 1$ medical record with a diagnosis for relapsed $\mathrm{MM}$ or $\mathrm{MM}$ in remission prior to the first observed treatment for $\mathrm{MM}$, or first-line treatment with melphalan or doxorubicin (with or without corticosteroids) before an indicator of SCT.

\section{Outcome Definitions}

For time to next treatment, an event was defined as the start of the subsequent line of therapy, which was the date of the first occurrence of (a) treatment switch, (b) treatment addon, (c) resumption of MM treatment (old or new regimen) after a treatment discontinuation (a 
Table 1 Analysis population

\begin{tabular}{|c|c|c|}
\hline & $n$ & $\begin{array}{l}\text { \% } \\
\text { Remaining }\end{array}$ \\
\hline \multicolumn{3}{|l|}{ Inclusion criteria } \\
\hline $\begin{array}{l}\text { Patients with } \geq 2 \text { medical records with a diagnosis for MM at least } 30 \text { days apart but no more than } \\
365 \text { days apart }\end{array}$ & 45,663 & - \\
\hline $\begin{array}{l}\text { Patients with } \geq 1 \text { medical record with a procedure code or a prescription fill for an MM treatment } \\
\text { at anytime }\end{array}$ & 21,324 & $47 \%$ \\
\hline $\begin{array}{l}\text { Patients who were initiated on the first MM treatment within } 1 \text { month prior to or any time after } \\
\text { the first observed diagnosis for MM }\end{array}$ & 20,177 & $95 \%$ \\
\hline Patients with their first observed MM treatment (defined as the index date) on or after 2012 & 16,784 & $83 \%$ \\
\hline Patients aged $\geq 18$ years as of the first observed MM treatment & 16,779 & $100 \%$ \\
\hline Patient enrolled in an integrated delivery network (IDN) & 10,939 & $65 \%$ \\
\hline \multicolumn{3}{|l|}{ Exclusion criteria } \\
\hline $\begin{array}{l}\text { Patients with an indicator of enrollment in a clinical trial on or after first observed treatment for } \\
\text { MM }\end{array}$ & 10,244 & $94 \%$ \\
\hline $\begin{array}{l}\text { Patients with } \geq 2 \text { medical records on different days with a diagnosis for a blood cancer other than } \\
\text { MM anytime }\end{array}$ & 9354 & $91 \%$ \\
\hline $\begin{array}{l}\text { Patients with a diagnosis for neoplasms of unspecified behavior (ICD-9-CM: 239; ICD-10-CM: } \\
\text { D49) on or after the first observed MM diagnosis }\end{array}$ & 8732 & $93 \%$ \\
\hline $\begin{array}{l}\text { Patients with } \geq 2 \text { medical records with a diagnosis for malignant neoplasm within } 2 \text { years prior to } \\
\text { the index date }\end{array}$ & 6468 & $74 \%$ \\
\hline Patient with an indicator of SCT any time prior to the index date & 5997 & $93 \%$ \\
\hline $\begin{array}{l}\text { Patients with } \geq 1 \text { medical record with a diagnosis for relapse/remission MM (ICD-9-CM: } 203.01 \\
\text { or 203.02; ICD-10-CM: C90.01 or C90.02) any time prior to the index date }\end{array}$ & 5186 & $86 \%$ \\
\hline
\end{tabular}

$M M$ multiple myeloma, $S C T$ stem cell transplant

drop of all therapeutic agents of the treatment regimen for $>90$ days), or (d) death. For overall survival, an event was defined as death.

\section{Subgroups}

To be included in the asthma group, patients had $\geq 1$ medical record with a diagnosis for asthma during the 12-month baseline period prior to initiating treatment. To be included in the COPD group, patients had $\geq 1$ medical record with a diagnosis for COPD during the 12-month baseline period prior to initiating treatment. To be included in the asthma or
COPD group, patients had $\geq 1$ medical record with a diagnosis for asthma or COPD during the 12-month baseline period prior to initiating treatment.

\section{Statistical Analysis}

Patient characteristics were summarized by line of therapy for the first four lines of therapy and replicated separately among the following subgroups: (a) patients with COPD, (b) patients without COPD, (c) patients with asthma, (d) patients without asthma, (e) patients with either asthma or COPD (asthma/COPD), and 
(f) patients with neither asthma nor COPD. Mean, standard deviation, and median are presented for continuous variables, and the frequency and percentage are presented for categorical variables.

For time-to-next-treatment analyses, patients were observed from the line of therapy initiation to start of the subsequent line of therapy. Patients without a subsequent line of therapy were censored at the earliest of death, the date of their last medical activity, or the end of the study period. For overall survival analyses, patients were observed from the line of therapy initiation to date of death, or patients without an observed date of death were censored at the end of the study period or the date of last medical activity.

Patients with asthma, COPD, or asthma/ COPD were compared with patients without asthma, COPD, or asthma/COPD for time to next treatment and overall survival using a onesided log-rank test stratified by age. Cox proportional hazard models were used to estimate the hazard ratios (HR) and 95\% confidence intervals (CI) for time to next treatment and overall survival, adjusted for age, sex, race, geographic region, insurance type, and Quan-Charlson comorbidity index (QCCI).

\section{RESULTS}

\section{Patient Characteristics}

A total of 5186 patients with MM were included in the analysis (Table 2). Of these patients, $10.1 \%(n=524)$ had a COPD diagnosis at baseline, $7.2 \%(n=373)$ had an asthma diagnosis at baseline, and $15.4 \%(n=799)$ had a diagnosis of asthma or COPD at baseline. The most commonly observed comorbidities among all MM patients and among those MM patients with asthma/COPD included cardiovascular disease, diabetes, and renal impairment. Both patients with asthma or COPD and patients without asthma or COPD had a median age of 69 years, and similar proportions were observed across the age categories.

The second-line analysis included 2386 patients (161 [6.7\%] with asthma and 184
[7.7\%] with COPD). The third-line analysis included 1064 patients (68 [6.4\%] with asthma and 78 [7.3\%] with COPD). The fourth-line analysis included 474 patients (33 [7.0\%] with asthma and 28 [5.9\%] with COPD).

A description of asthma/COPD and MM treatments are shown in Tables 3 and 4, respectively. The most common treatments for patients with asthma/COPD were systemic corticosteroids $(76.7 \%$, asthma; $72.7 \%$, COPD), oral corticosteroids $(70.5 \%$, asthma; $70.0 \%$, COPD), and short-acting beta agonists (56.6\%, asthma; 55.7\%, COPD) (Table 3).

Approximately half of patients received firstline anti-myeloma treatment with bortezomib or lenalidomide (Table 4). Overall, $31.1 \%$ of patients received a two-agent combination. Evidence for receipt of SCT was low across the groups, particularly for patients with COPD. Steroids were assumed to be present in treatment lines due to concerns about adequate capture of steroid use.

\section{Time to Next Treatment}

\section{First to Second Line}

The median time to next treatment for patients with COPD was significantly longer compared with patients with no COPD (27.56 vs. 22.10 months; adjusted HR $0.71 ; 95 \%$ CI $0.61-0.83 ; p=0.04$; Fig. $1 \mathrm{a})$. There was no significant difference in time to next treatment between patients with asthma and patients without asthma (25.83 vs. 22.56 months; adjusted HR 0.88 ; 95\% CI 0.74-1.04). The median time to next treatment for patients with asthma or COPD was significantly longer compared with patients with no asthma nor COPD (25.83 vs. 22.38 months; adjusted HR 0.80; 95\% CI 0.70-0.90).

\section{Second to Third Line}

No significant differences in time to third-line treatment were observed in patients with/without COPD (18.93 vs. 18.66 months; HR 1.07; 95\% CI 0.85-1.35), with/without asthma (19.03 vs. 18.66 months; HR 0.93 ; 95\% CI $0.73-1.20$ ), or with/without asthma or COPD (18.66 vs. 
Table 2 Patient characteristics

First line

\begin{tabular}{lllllll}
\hline All & COPD & No COPD & Asthma & No asthma & COPD or & Neither COPD nor \\
$(N=5186)$ & $(n=524)$ & $(n=4662)$ & $(n=373)$ & $(n=4813)$ & asthma & asthma \\
& & & & & $(n=799)$ & $(n=4387)$
\end{tabular}

\begin{tabular}{|c|c|c|c|c|c|c|c|}
\hline \multicolumn{8}{|l|}{ At the index date ${ }^{a}$} \\
\hline \multicolumn{8}{|l|}{ Age (years) } \\
\hline Mean (SD) & $68.4(11.0)$ & $70.2(9.8)$ & $68.2(11.1)$ & $\begin{array}{l}67.6 \\
\quad(10.2)\end{array}$ & $68.5(11.0)$ & $69.2(10.0)$ & $68.2(11.1)$ \\
\hline Median & 69 & 70 & 69 & 68 & 69 & 69 & 69 \\
\hline \multicolumn{8}{|c|}{ Age categories, $n(\%)$} \\
\hline$<50$ & $267(5)$ & $7(1)$ & $260(6)$ & $17(5)$ & $250(5)$ & $21(3)$ & $246(6)$ \\
\hline $50-54$ & $258(5)$ & $18(3)$ & $240(5)$ & $19(5)$ & $239(5)$ & $34(4)$ & $224(5)$ \\
\hline $55-59$ & $488(9)$ & $49(9)$ & $439(9)$ & $40(11)$ & $448(9)$ & $75(9)$ & $413(9)$ \\
\hline $60-64$ & $814(16)$ & $78(15)$ & $736(16)$ & $62(17)$ & $752(16)$ & $122(15)$ & $692(16)$ \\
\hline $65-69$ & $833(16)$ & $92(18)$ & $741(16)$ & $75(20)$ & $758(16)$ & $150(19)$ & $683(16)$ \\
\hline $70-74$ & $814(16)$ & $88(17)$ & $726(16)$ & $57(15)$ & $757(16)$ & $133(17)$ & $681(16)$ \\
\hline $75-79$ & $775(15)$ & $86(16)$ & $689(15)$ & $57(15)$ & $718(15)$ & $127(16)$ & $648(15)$ \\
\hline $80-84$ & $709(14)$ & $74(14)$ & $635(14)$ & $31(8)$ & $678(14)$ & $95(12)$ & $614(14)$ \\
\hline$\geq 85$ & $228(4)$ & $32(6)$ & $196(4)$ & $15(4)$ & $213(4)$ & $42(5)$ & $186(4)$ \\
\hline \multicolumn{8}{|l|}{ Race, $n(\%)$} \\
\hline Caucasian & $3953(76)$ & $399(76)$ & $3554(76)$ & $258(69)$ & $3695(77)$ & $590(74)$ & $3363(77)$ \\
\hline \multicolumn{7}{|l|}{ American } & $736(17)$ \\
\hline Asian & $55(1)$ & $1(0)$ & $54(1)$ & $5(1)$ & $50(1)$ & $6(1)$ & $49(1)$ \\
\hline Other/unknown & $275(5)$ & $19(4)$ & $256(5)$ & $20(5)$ & $255(5)$ & $36(5)$ & $239(5)$ \\
\hline \multicolumn{8}{|l|}{ Ethnicity, $n(\%)$} \\
\hline Hispanic & $201(4)$ & $15(3)$ & $186(4)$ & $18(5)$ & $183(4)$ & $33(4)$ & $168(4)$ \\
\hline Non-Hispanic & $4725(91)$ & $486(93)$ & $4239(91)$ & $337(90)$ & $4388(91)$ & $730(91)$ & $3995(91)$ \\
\hline Unknown & $260(5)$ & $23(4)$ & $237(5)$ & $18(5)$ & $242(5)$ & $36(5)$ & $224(5)$ \\
\hline \multicolumn{8}{|l|}{ Sex, $n(\%)$} \\
\hline Female & $2456(47)$ & $239(46)$ & $2217(48)$ & $206(55)$ & $2250(47)$ & $396(50)$ & $2060(47)$ \\
\hline Male & $2724(53)$ & $285(54)$ & $2439(52)$ & $166(45)$ & $2558(53)$ & $402(50)$ & $2322(53)$ \\
\hline Unknown & $6(0)$ & & $6(0)$ & $1(0)$ & $5(0)$ & $1(0)$ & $5(0)$ \\
\hline \multicolumn{8}{|c|}{ Region of residence, $n(\%)$} \\
\hline Northeast & $708(14)$ & $63(12)$ & $645(14)$ & $49(13)$ & $659(14)$ & $96(12)$ & $612(14)$ \\
\hline Midwest & $2808(54)$ & $310(59)$ & $2498(54)$ & $229(61)$ & $2579(54)$ & $472(59)$ & $2336(53)$ \\
\hline South & $1147(22)$ & 99 (19) & $1048(22)$ & $64(17)$ & $1083(23)$ & $152(19)$ & $995(23)$ \\
\hline
\end{tabular}


Table 2 continued

\begin{tabular}{|c|c|c|c|c|c|c|c|}
\hline & \multicolumn{7}{|l|}{ First line } \\
\hline & $\begin{array}{l}\text { All } \\
(N=5186)\end{array}$ & $\begin{array}{l}\text { COPD } \\
(n=524)\end{array}$ & $\begin{array}{l}\text { No COPD } \\
(n=4662)\end{array}$ & $\begin{array}{l}\text { Asthma } \\
(n=373)\end{array}$ & $\begin{array}{l}\text { No asthma } \\
(n=4813)\end{array}$ & $\begin{array}{l}\text { COPD or } \\
\text { asthma } \\
(n=799)\end{array}$ & $\begin{array}{l}\text { Neither COPD nor } \\
\text { asthma } \\
(n=4387)\end{array}$ \\
\hline West & $414(8)$ & $41(8)$ & $373(8)$ & $23(6)$ & $391(8)$ & $61(8)$ & $353(8)$ \\
\hline $\begin{array}{l}\text { Other/ } \\
\text { unknown }\end{array}$ & $109(2)$ & $11(2)$ & $98(2)$ & $8(2)$ & $101(2)$ & $18(2)$ & $91(2)$ \\
\hline \multicolumn{8}{|c|}{ Calendar year, $n(\%)$} \\
\hline 2012 & $453(8.74)$ & $37(7.06)$ & $416(8.92)$ & $19(5.09)$ & $434(9.02)$ & $52(6.51)$ & $401(9.14)$ \\
\hline 2013 & $570(10.99)$ & $52(9.92)$ & $\begin{array}{l}518 \\
\quad(11.11)\end{array}$ & $34(9.12)$ & $\begin{array}{l}536 \\
\quad(11.14)\end{array}$ & $79(9.89)$ & $491(11.19)$ \\
\hline 2014 & $658(12.69)$ & $\begin{array}{l}67 \\
\quad(12.79)\end{array}$ & $\begin{array}{l}591 \\
\quad(12.68)\end{array}$ & $\begin{array}{l}49 \\
(13.14)\end{array}$ & $\begin{array}{l}609 \\
\quad(12.65)\end{array}$ & $107(13.39)$ & $551(12.56)$ \\
\hline 2015 & $707(13.63)$ & $\begin{array}{l}68 \\
\quad(12.98)\end{array}$ & $\begin{array}{l}639 \\
\quad(13.71)\end{array}$ & $\begin{array}{l}41 \\
\quad(10.99)\end{array}$ & $\begin{array}{l}666 \\
\quad(13.84)\end{array}$ & $99(12.39)$ & $608(13.86)$ \\
\hline 2016 & $772(14.89)$ & $\begin{array}{l}72 \\
(13.74)\end{array}$ & $\begin{array}{l}700 \\
\quad(15.02)\end{array}$ & $\begin{array}{l}70 \\
\quad(18.77)\end{array}$ & $\begin{array}{l}702 \\
\quad(14.59)\end{array}$ & $118(14.77)$ & $654(14.91)$ \\
\hline 2017 & $768(14.81)$ & $\begin{array}{l}94 \\
\quad(17.94)\end{array}$ & $\begin{array}{l}674 \\
\quad(14.46)\end{array}$ & $\begin{array}{l}67 \\
\quad(17.96)\end{array}$ & $\begin{array}{l}701 \\
\quad(14.56)\end{array}$ & $141(17.65)$ & $627(14.29)$ \\
\hline 2018 & $646(12.46)$ & $\begin{array}{l}72 \\
(13.74)\end{array}$ & $\begin{array}{l}574 \\
\quad(12.31)\end{array}$ & $\begin{array}{l}50 \\
\quad(13.40)\end{array}$ & $\begin{array}{l}596 \\
\quad(12.38)\end{array}$ & $108(13.52)$ & $538(12.26)$ \\
\hline 2019 & $612(11.80)$ & $\begin{array}{l}62 \\
(11.83)\end{array}$ & $\begin{array}{l}550 \\
\quad(11.80)\end{array}$ & $\begin{array}{l}43 \\
\quad(11.53)\end{array}$ & $\begin{array}{l}569 \\
\quad(11.82)\end{array}$ & $95(11.89)$ & $517(11.78)$ \\
\hline \multicolumn{8}{|c|}{ Time from MM diagnosis to treatment line initiation (months) } \\
\hline Mean (SD) & $9.1(17.2)$ & $6.9(13.8)$ & $9.4(16.5)$ & $7.3(14.8)$ & $9.3(17.4)$ & $7.2(14.7)$ & $9.5(17.6)$ \\
\hline \multicolumn{8}{|c|}{ Insurance type, $n(\%)$} \\
\hline Commercial & $1630(31)$ & $117(22)$ & $1513(32)$ & $128(34)$ & $1502(31)$ & $223(28)$ & $1407(32)$ \\
\hline Medicare & $2755(53)$ & $314(60)$ & $2441(52)$ & $186(50)$ & $2569(53)$ & $449(56)$ & $2306(53)$ \\
\hline Medicaid & $220(4)$ & $38(7)$ & $182(4)$ & $27(7)$ & $193(4)$ & $51(6)$ & $169(4)$ \\
\hline $\begin{array}{l}\text { Other payor } \\
\text { type }\end{array}$ & $83(2)$ & $8(2)$ & $75(2)$ & $2(1)$ & $81(2)$ & $10(1)$ & $73(2)$ \\
\hline Uninsured & $64(1)$ & $8(2)$ & $56(1)$ & $7(2)$ & $57(1)$ & $12(2)$ & $52(1)$ \\
\hline Unknown & $275(5)$ & $32(6)$ & $243(5)$ & $19(5)$ & $256(5)$ & $45(6)$ & $230(5)$ \\
\hline Missing & $159(3)$ & $7(1)$ & $152(3)$ & $4(1)$ & $155(3)$ & $9(1)$ & $150(3)$ \\
\hline \multicolumn{8}{|c|}{ Integrated patient, $n(\%)$} \\
\hline Yes & $1320(25)$ & $125(24)$ & $1195(26)$ & $119(32)$ & $1201(25)$ & $215(27)$ & $1105(25)$ \\
\hline No & $3866(75)$ & $399(76)$ & $3467(74)$ & $254(68)$ & $3612(75)$ & $584(73)$ & $3282(75)$ \\
\hline
\end{tabular}


Table 2 continued

First line

\begin{tabular}{lllllll}
\hline All & COPD & No COPD & Asthma & No asthma & COPD or & Neither COPD nor \\
$(N=5186)$ & $(n=524)$ & $(n=4662)$ & $(n=373)$ & $(n=4813)$ & asthma & asthma \\
& & & & & $(n=799)$ & $(n=4387)$
\end{tabular}

During the baseline period ${ }^{\mathrm{b}}$

Quan-Charlson comorbidity index (excluding MM)

\begin{tabular}{llllllll} 
Mean (SD) & $2.7(3.1)$ & $5.2(3.2)$ & $2.4(3.0)$ & $4.7(3.2)$ & $2.6(3.1)$ & $5(3.2)$ & $2.3(3.0)$ \\
Comorbidities, $n(\%)$ & & & & & & \\
Anemia & $751(14)$ & $115(22)$ & $636(14)$ & $79(21)$ & $672(14)$ & $166(21)$ & $585(13)$ \\
$\begin{array}{l}\text { Cardiovascular } \\
\text { disease }\end{array}$ & $2659(51)$ & $386(74)$ & $2273(49)$ & $279(75)$ & $2380(49)$ & $582(73)$ & $2077(47)$ \\
$\begin{array}{l}\text { Diabetes } \\
\text { Hypercalcemia }\end{array}$ & $1094(21)$ & $175(33)$ & $919(20)$ & $136(36)$ & $958(20)$ & $271(34)$ & $823(19)$ \\
$\begin{array}{l}\text { Peripheral } \\
\text { neuropathy }\end{array}$ & $357(7)$ & $58(11)$ & $299(6)$ & $29(8)$ & $328(7)$ & $81(10)$ & $276(6)$ \\
$\begin{array}{l}\text { Renal impairment } \\
\text { Skeletal-related }\end{array}$ & $1363(26)$ & $215(41)$ & $1148(25)$ & $134(36)$ & $1229(26)$ & $303(38)$ & $1060(24)$ \\
events & $878(17)$ & $130(25)$ & $748(16)$ & $75(20)$ & $803(17)$ & $185(23)$ & $693(16)$ \\
$\begin{array}{l}\text { Thrombocytopenia } \\
\text { Thro }\end{array}$ & $546(11)$ & $87(17)$ & $459(10)$ & $54(14)$ & $492(10)$ & $122(15)$ & $424(10)$ \\
\hline
\end{tabular}

$M M$ multiple myeloma, $S D$ standard deviation

a Index date was defined as the start for the treatment line

b Baseline period was defined as the 12-month period prior to each treatment start date, excluding the index date

18.70 months; HR $1.02 ; 95 \%$ CI $0.85-1.22$; Fig. 1b).

\section{Third to Fourth Line}

No significant differences in time to fourth-line treatment were observed in patients with/without asthma (15.90 vs. 14.46 months; HR 1.02; 95\% CI 0.71-1.46), with/without COPD (15.73 vs. 14.46 months; HR 0.96; 95\% CI 0.65-1.42), or with/without asthma or COPD (15.90 vs. 14.26 months; HR 0.98; 95\% CI 0.74-1.30; Fig. 1c).

\section{Overall Survival}

\section{Overall Survival: Line 1}

Overall survival from the start of first-line therapy was significantly worse among patients with COPD compared with patients without COPD (38.8 vs. 67.9 months; adjusted HR 1.30; 95\% CI 1.12-1.51; $p<0.005$; Fig. 2). No significant differences in overall survival from firstline therapy were observed in patients with/ without asthma (73.3 vs. 60.9 months; adjusted HR 0.90; 95\% CI 0.75-1.10), or with/without asthma or COPD (45.03 vs. 66.86 months; adjusted HR 1.11; 95\% CI 0.98-1.27).

\section{Overall Survival: Line 2}

MM patients with COPD had worse overall survival from the start of second-line therapy compared with patients without COPD (35.70 vs. 49.86 months); however, this difference was not statistically significant in multivariable adjusted models (adjusted HR 1.26; 95\% CI $0.98-1.61)$. No significant differences in overall survival were observed for MM patients with/ 
Table 3 Description of asthma and COPD treatments

\begin{tabular}{|c|c|c|}
\hline & \multicolumn{2}{|l|}{ First line } \\
\hline & $\begin{array}{l}\text { Asthma } \\
n=373\end{array}$ & $\begin{array}{l}\text { COPD } \\
n=524\end{array}$ \\
\hline \multicolumn{3}{|l|}{ Asthma + COPD treatments, $n(\%)$} \\
\hline $\operatorname{SABA}(\mathrm{Y} / \mathrm{N})$ & $211(56.6)$ & $292(55.7)$ \\
\hline LABA $(\mathrm{Y} / \mathrm{N})$ & $18(4.8)$ & $32(6.1)$ \\
\hline $\mathrm{ICS}(\mathrm{Y} / \mathrm{N})$ & $31(8.3)$ & $33(6.3)$ \\
\hline ICS dose low & 0 & $2(0.4)$ \\
\hline ICS dose medium & $26(7.0)$ & $27(5.2)$ \\
\hline ICS dose high & $7(1.9)$ & $8(1.5)$ \\
\hline Leukotriene modifiers $(\mathrm{Y} / \mathrm{N})$ & $53(14.2)$ & $31(5.9)$ \\
\hline Theophylline (Y/N) & $3(0.8)$ & $6(1.1)$ \\
\hline Tiotropium $(\mathrm{Y} / \mathrm{N})$ & $26(7.0)$ & $69(13.2)$ \\
\hline OCS use $(\mathrm{Y} / \mathrm{N})$ & $263(70.5)$ & $367(70.0)$ \\
\hline Systemic corticosteroids $(\mathrm{Y} / \mathrm{N})$ & $286(76.7)$ & $381(72.7)$ \\
\hline Controller medication & $131(35.1)$ & $171(32.6)$ \\
\hline 1 type of controller mediation $(\mathrm{Y} / \mathrm{N})$ & $91(24.4)$ & $119(22.7)$ \\
\hline 2 types of controller medications $(\mathrm{Y} / \mathrm{N})$ & $32(8.6)$ & $44(8.4)$ \\
\hline$\geq 3$ types of controller medications $(\mathrm{Y} / \mathrm{N})$ & $8(2.1)$ & $8(1.5)$ \\
\hline ICS only & $3(0.8)$ & $1(0.2)$ \\
\hline $\mathrm{ICS}+\mathrm{SABA}$ & $10(2.7)$ & $14(2.7)$ \\
\hline $\mathrm{ICS}+\mathrm{LABA}$ & $98(26.3)$ & $126(24.0)$ \\
\hline Triple or more therapy & $13(3.5)$ & $16(3.1)$ \\
\hline \multicolumn{3}{|l|}{ COPD specific } \\
\hline LAMA $(\mathrm{Y} / \mathrm{N})$ & $61(16.4)$ & $129(24.6)$ \\
\hline $\mathrm{LAMA}+\mathrm{LABA}(\mathrm{Y} / \mathrm{N})$ & $5(1.3)$ & $9(1.7)$ \\
\hline Long-term oxygen use $(\mathrm{Y} / \mathrm{N})$ & $1(0.3)$ & $8(1.5)$ \\
\hline Systematic antibiotics $(\mathrm{Y} / \mathrm{N})$ & $217(58.2)$ & $303(57.8)$ \\
\hline
\end{tabular}

ICS inhaled corticosteroid, $L A B A$ long-acting beta agonist, $L A M A$ long-acting muscarinic antagonist, $O C S$ oral corticosteroid, $S A B A$ short-acting beta agonist, $Y / N$ yes or no response

without asthma (63.66 vs. 48.13 months; adjusted HR 1.01; 95\% CI 0.76-1.35), or with/ without asthma or COPD (39.56 vs. 48.96 months; adjusted HR 1.15; 95\% CI
0.94-1.41). Similarly, numerically worse overall survival was observed from the start of thirdand fourth-line therapy among MM patients with COPD (data not shown). 


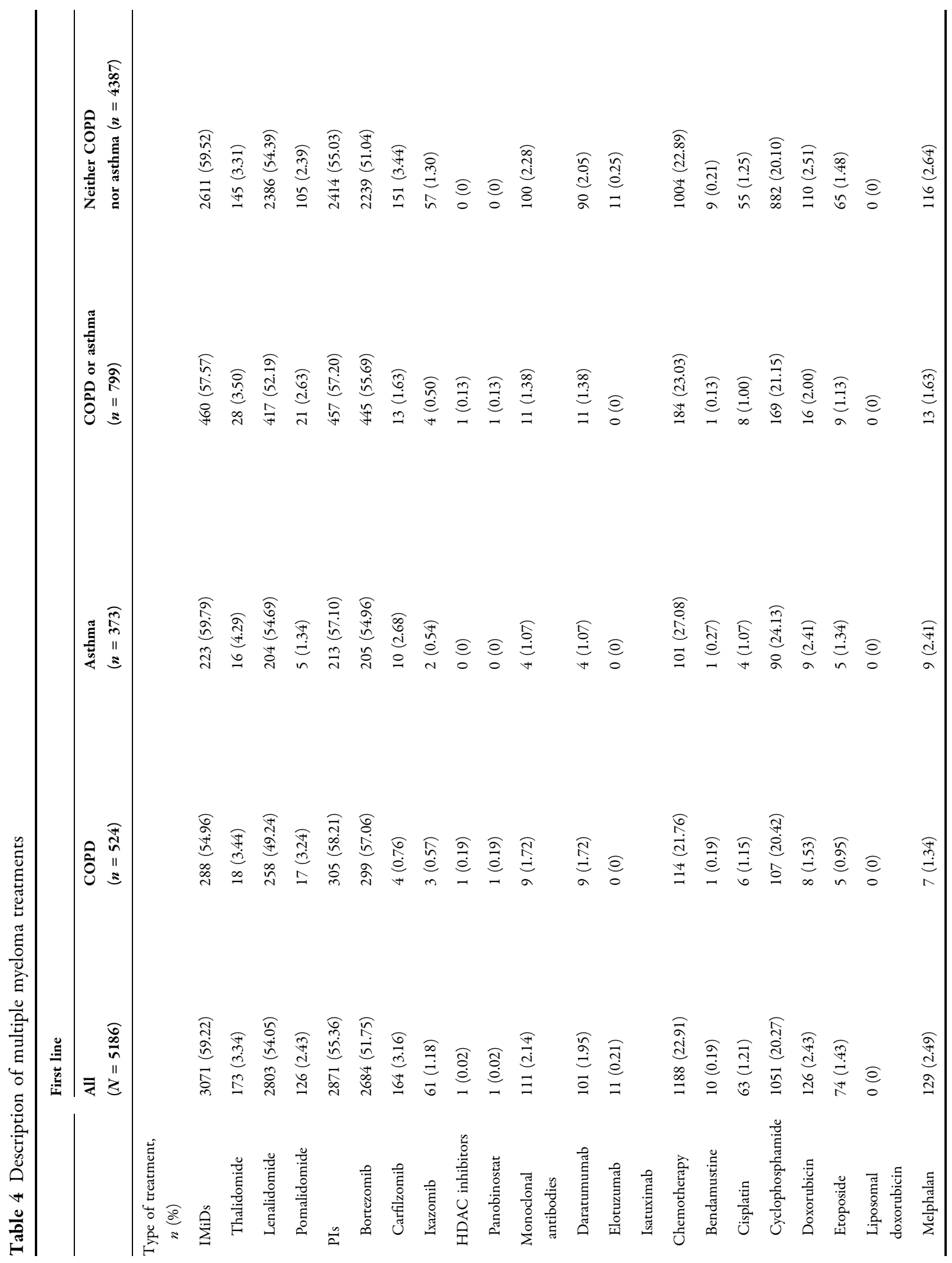




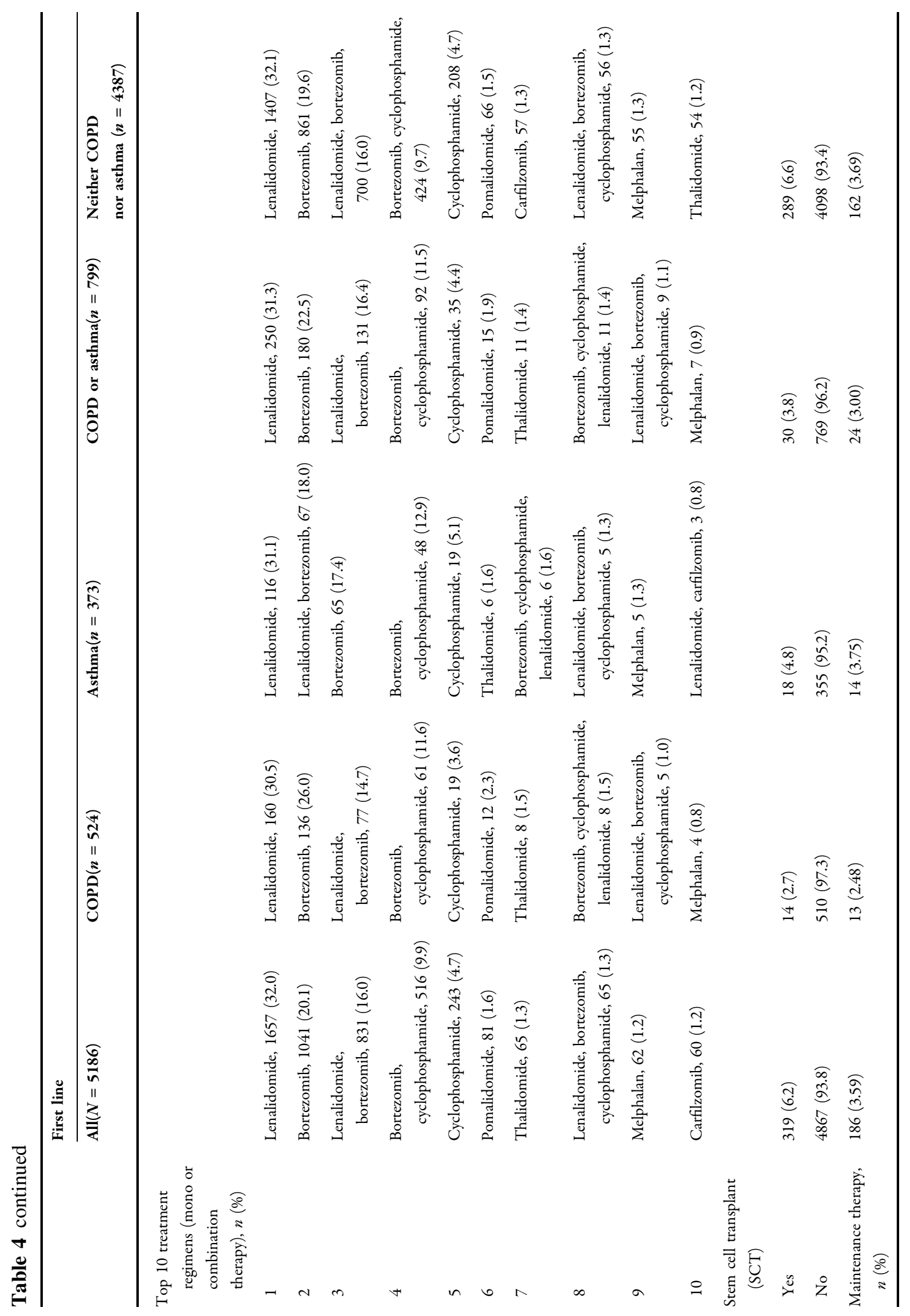




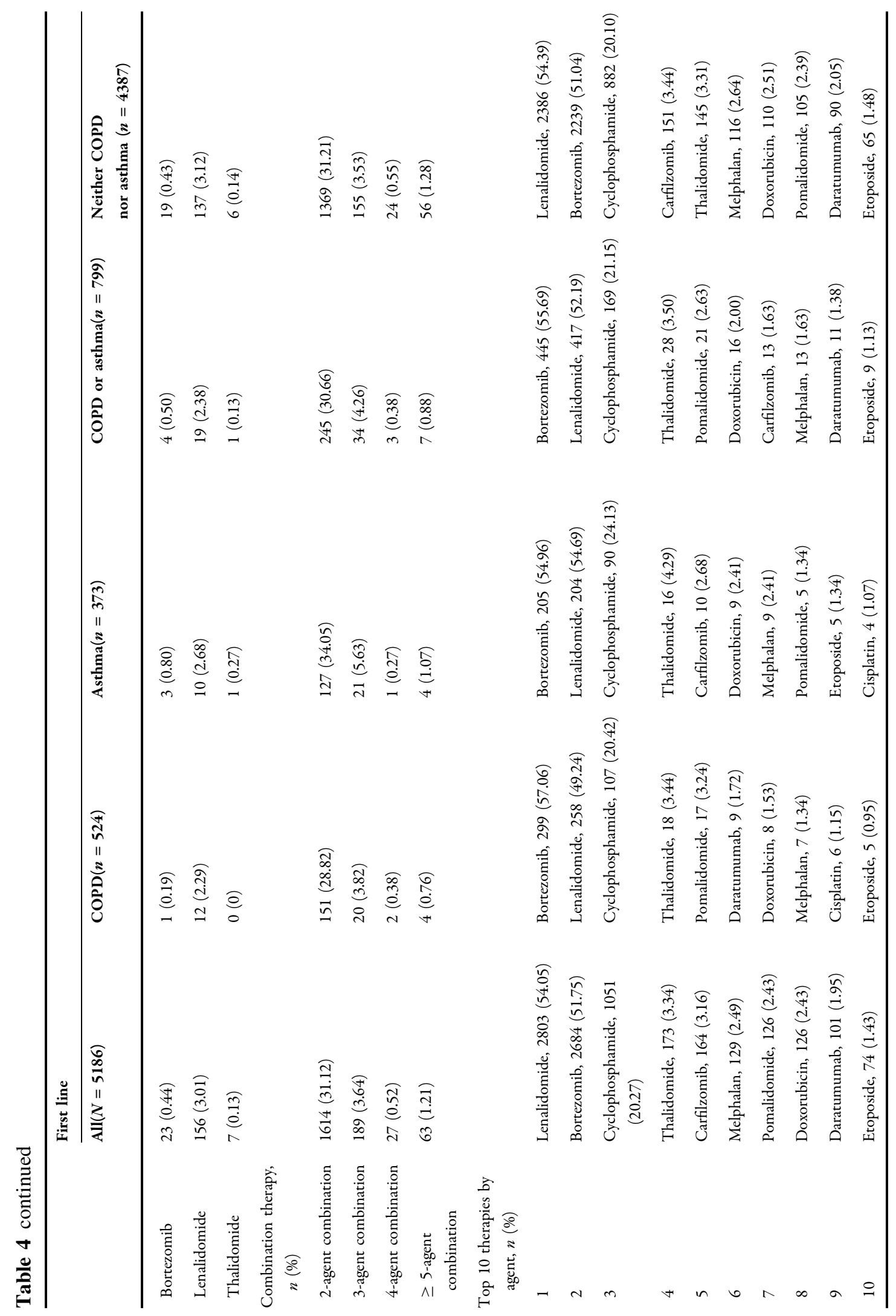




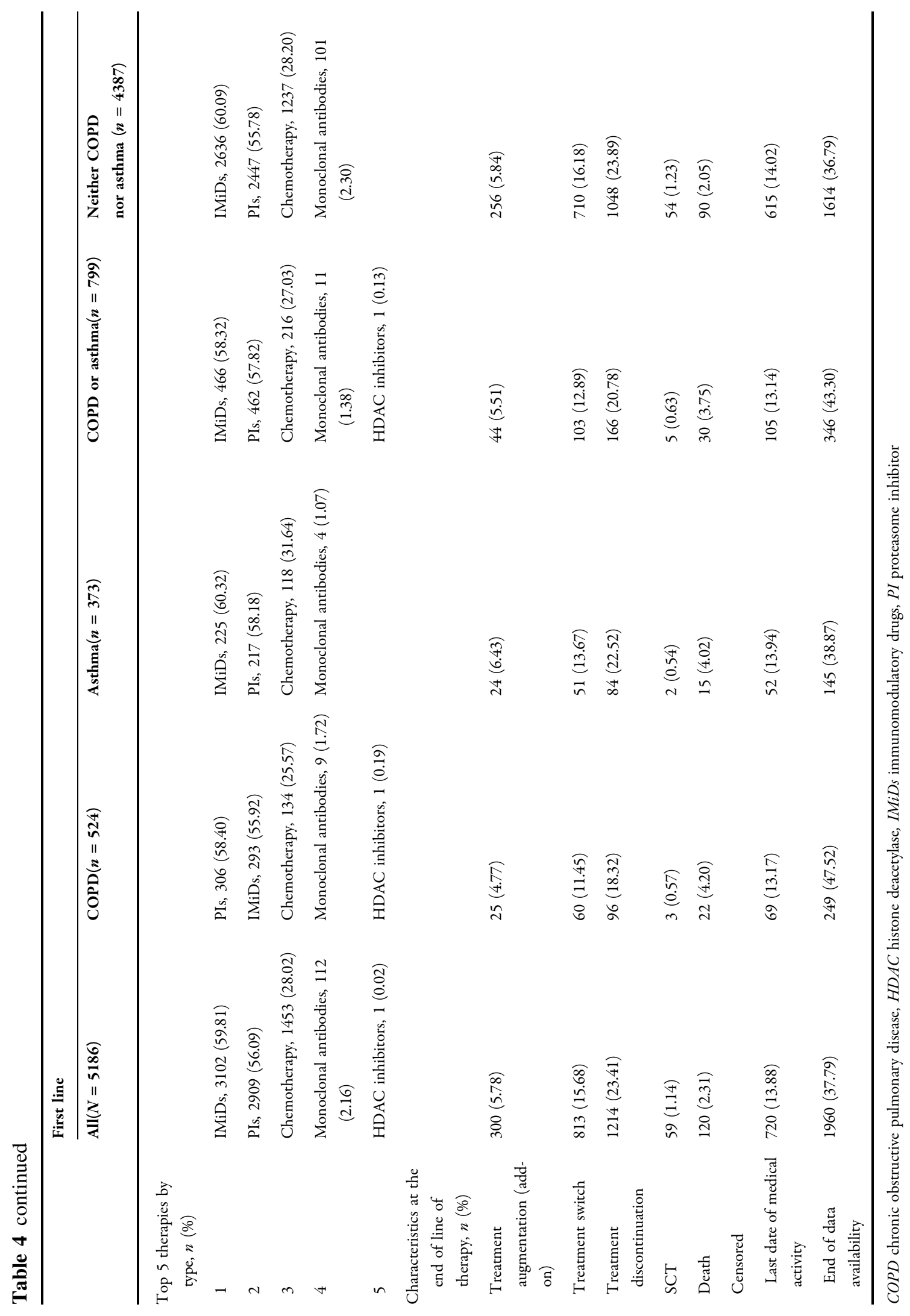


(a)

Time to next treatment - Line 1

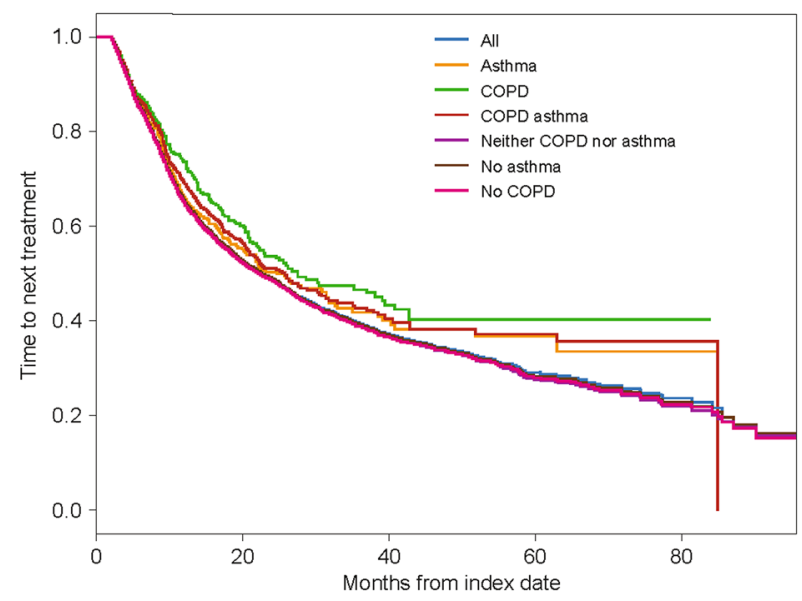

(b)

Time to next treatment - Line 2

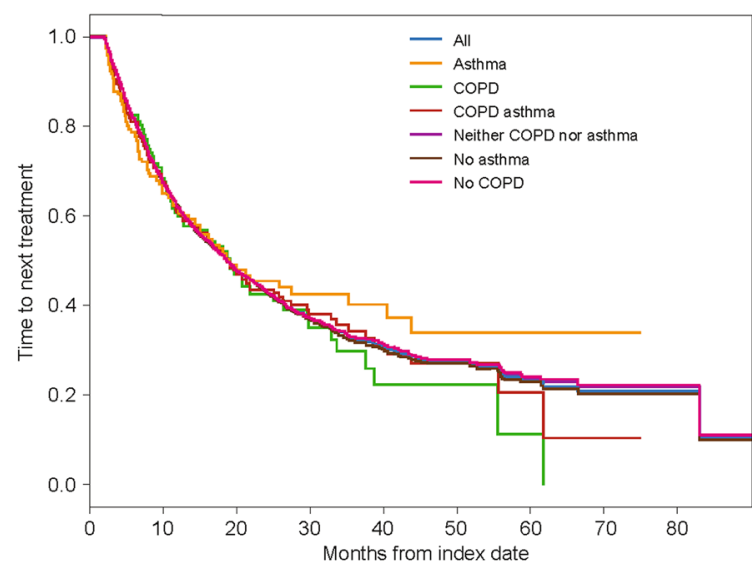

(c)

Time to next treatment - Line 3

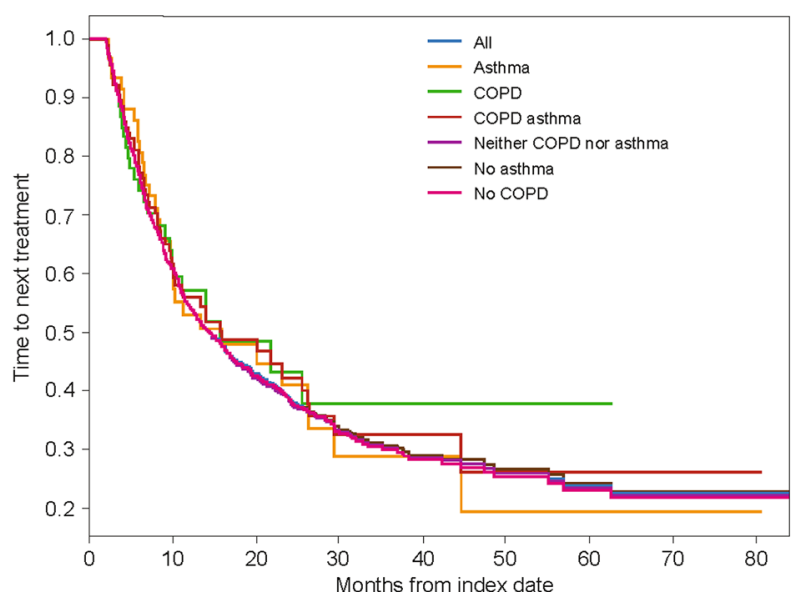

Fig. 1 Time to next treatment. Kaplan-Meier analyses were used to estimate time to next treatment from first to second line (a), second to third line (b), and third to fourth line (c). Patients were observed from the line of therapy initiation (index date) to the subsequent line of therapy initiation (event; earliest of second-line index date or date of death), or the observation period of patients without a subsequent line of therapy was censored at the

\section{DISCUSSION}

In this study of patients with MM from the Optum EHR database, approximately 15\% had a previous asthma or COPD diagnosis. Time from first- to second-line treatment was significantly longer for patients with a diagnosis of COPD or end of follow-up (censoring; i.e., first event end of data availability, and end of continuous medical activity). Patients at risk were defined as the total number of patients who were still observed (no prior event and no censoring) at the specific time period (i.e., patients without the study event prior to that time point and who were still followed)

a diagnosis of asthma or COPD. Overall survival from start of first-line therapy was significantly worse among $\mathrm{MM}$ patients with COPD; numerically worse overall survival was observed from the start of lines 2-4.

In the current study of 5186 patients with MM, $15 \%$ of patients had an asthma or COPD diagnosis. This is similar to the proportion of 


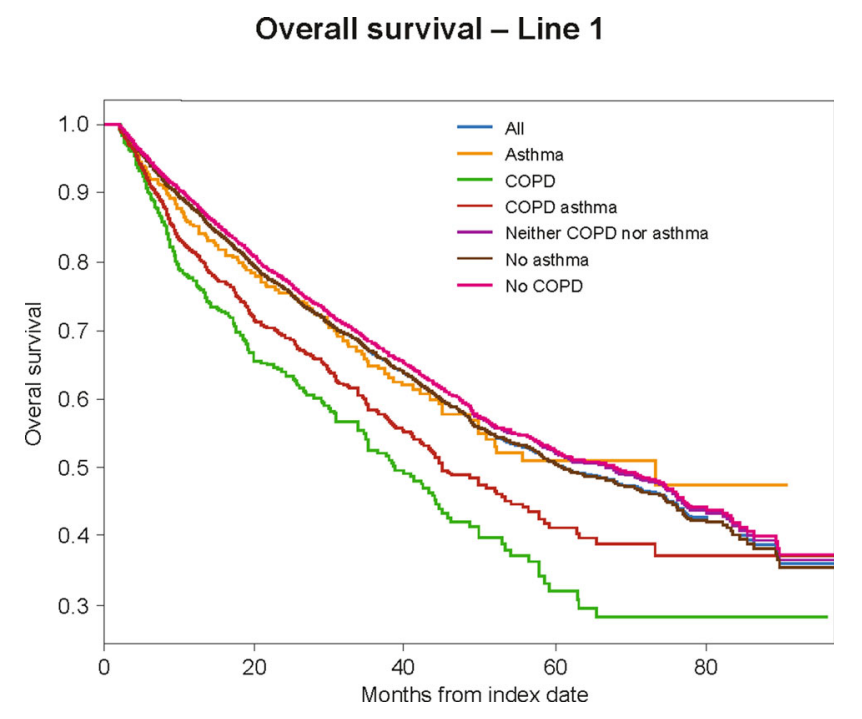

Fig. 2 Overall survival. Kaplan-Meier analyses were used to estimate overall survival. Patients were observed from the line of therapy initiation to death (event), or the observation period of patients without a subsequent line of therapy was censored at the end of follow-up (censoring; i.e., first event end of data availability, and end of

patients in the ICARIA-MM study who had asthma or COPD ( 10\%) [10]. In ICARIA-MM, asthma and COPD were not used as exclusion criteria. Previous MM studies have used COPD/ pulmonary disease as an exclusion criterion (e.g., POLLUX; ELOQUENT-2 [if uncontrolled]; CASTOR; CANDOR; MAIA; CASSIOPEIA) [11-16]. Asthma and COPD were used as exclusion criteria in these studies due to concern for bronchial hyperreactivity, infusion reactions, and need for additional pre- and postmedications [19]. Because of this, there are limited data in patients with MM and COPD who have been treated with monoclonal antibodies to date.

Based on the assessment of MM treatments in the current study, real-world monoclonal antibody use is not reported frequently to date, lagging behind treatment guidelines [20]. Within the small number of patients who received monoclonal antibody treatment, there was a trend towards more use in patients without asthma/COPD (2.28\%) than with asthma/ COPD $(1.38 \%)$, suggesting that there may be some reluctance to treat due to concern for bronchial hyperreactivity, infusion reactions, continuous medical activity). Patients at risk were defined as the total number of patients who were still observed (no prior event and no censoring) at the specific time period (i.e., patients without the study event prior to that time point and who were still followed)

and to paucity of data due to exclusion of patients from clinical trials [11-16, 19].

Extending time to next treatment can frequently be a main objective of MM therapy and can also be interpreted as a measure of delayed progression [21]. Based on the lack of significant differences in time to next treatment between patients with and without COPD or asthma, the comorbidity of COPD or asthma does not automatically portend a worse prognosis, and these patients should be considered for inclusion in future clinical trials. In fact, patients with COPD exhibited a significantly longer time from first- to second-line therapy compared with patients without COPD. These results provide real-world data that may help inform clinical decisions related to therapies for $\mathrm{MM}$ patients with asthma and COPD.

In the current study, overall survival from first-line therapy was significantly worse among patients with COPD, and numerical differences were observed in the second through fourth line; however, we had limited power to detect significant differences in later treatment lines due to the fact that the number of patients with COPD decreased from 524 patients in line 1 to 
28 patients in line 4 . Results from a recent study also demonstrated significantly worse overall survival among patients with obstructive pulmonary defects [18]. The presence of peak expiratory flow and/or carbon monoxide diffusion capacity $<65 \%$ of predicted were independent prognostic factors of survival in the study. These pulmonary function parameters were not explored in the current study, however, providing areas of interest for additional real-world studies.

In the current study, higher proportions of patients with asthma/COPD had diabetes and cardiovascular and renal comorbidities compared with patients without asthma/COPD. Therefore, the discrepancy between the observed prolonged time to next treatment in early treatment lines and decreased overall survival for patients with COPD may be linked to decreased receipt of later-line treatment and more associated comorbidities.

Previous studies have reported preexisting moderate or severe pulmonary disease to be a negative predictor of survival among patients with MM in a Swedish registry-based population [22], and an association between higher allcause and myeloma-specific mortality and previous chronic pulmonary disease, independent of age [17].

Interestingly, numerically longer survival was observed in patients with asthma in lines 2 and 3 and in patients with COPD/asthma in line 3 of the current study. It is possible that a proportion of patients in the groups without a history of asthma or COPD had abnormal lung function, which may only be identified during spirometry testing [23, 24]. Additional studies are needed to better understand the relationship between preexisting pulmonary comorbidities and survival among patients with MM.

This study has some limitations. Patients were classified as having asthma and/or COPD based on the presence of at least one medical record with a diagnosis of asthma/COPD in the 12-month period prior to the index date, which may have resulted in some misclassification. As with all observational studies, there is the potential for unmeasured or residual confounding, though we adjusted for several potential confounders, including age and
QCCI. However, other factors, such as smoking status, were not accounted for, which may explain some of the differences in overall survival between subgroups. Additionally, the lower number of patients included in each subsequent line of therapy resulted in reduced power, limiting our ability to detect differences in outcomes between subgroups. Strengths of the study include the inclusion of real-world data on MM patients with asthma or COPD, which increases the available information on this patient subgroup. These data provide longer-term treatment and outcomes information that may be used to inform future studies on MM patients with pulmonary comorbidities.

\section{CONCLUSIONS}

Among 5186 patients with MM, approximately $15 \%$ had an asthma or COPD diagnosis at baseline. The most commonly observed comorbidities among all patients were cardiovascular disease, diabetes, and renal impairment, which were even higher among those with asthma or COPD. Time from first- to second-line treatment was significantly longer for patients with a diagnosis of COPD. Overall survival from start of first-line therapy was significantly worse among patients with COPD, with numerically worse overall survival in subsequent lines. These data suggest that patients with COPD do not experience a shorter time interval to next treatment, but they may exhibit worse overall survival from the start of first-line therapy. Future investigations with larger datasets may improve the understanding of the influence of individual treatments on outcomes in these patients with multiple myeloma and pulmonary comorbidities.

\section{ACKNOWLEDGEMENTS}

Funding. Sponsorship for this study and Rapid Service Fee were funded by Sanofi (Cambridge, MA, USA). 
Authorship. All named authors meet the International Committee of Medical Journal Editors (ICMJE) criteria for authorship for this article, take responsibility for the integrity of the work as a whole, and have given their approval for this version to be published

Authorship Contributions. All authors contributed to the interpretation of the data and were involved in the process of writing and reviewing this manuscript. All authors take complete responsibility for the integrity of the data and accuracy of the data analysis. The authors acknowledge medical writing assistance from Erin Burns-Tidmore, PhD, of Elevate Medical Affairs, contracted by Sanofi Genzyme for publication support services. The authors acknowledge programming support from Meriem Garsaa, of Quinten, contracted by Sanofi Genzyme for analytic support services.

Disclosures. Megan S. Rice is employed by Sanofi and may hold stock and/or stock options in the company. Sarah Naeger is employed by Sanofi and may hold stock and/or stock options in the company. Erin Singh is employed by Sanofi and may hold stock and/or stock options in the company.

Compliance with Ethics Guidelines. This article is based on previously conducted studies and does not contain any studies with human participants or animals performed by any of the authors.

Data Availability. The datasets generated during and/or analyzed during the current study are from the US Optum ${ }^{\circledR}$ de-identified electronic health record database housed in DARWIN, https://www.optum.com/business/ solutions/government/federal/data-analyticsfederal/clinical-data.html\#.

Open Access. This article is licensed under a Creative Commons Attribution-NonCommercial 4.0 International License, which permits any non-commercial use, sharing, adaptation, distribution and reproduction in any medium or format, as long as you give appropriate credit to the original author(s) and the source, provide a link to the Creative Commons licence, and indicate if changes were made. The images or other third party material in this article are included in the article's Creative Commons licence, unless indicated otherwise in a credit line to the material. If material is not included in the article's Creative Commons licence and your intended use is not permitted by statutory regulation or exceeds the permitted use, you will need to obtain permission directly from the copyright holder. To view a copy of this licence, visit http:// creativecommons.org/licenses/by-nc/4.0/.

\section{REFERENCES}

1. Kazandjian D. Multiple myeloma epidemiology and survival: a unique malignancy. Semin Oncol. 2016;43(6):676-81. https://doi.org/10.1053/j. seminoncol.2016.11.004.

2. Rajkumar SV, Kumar S. Multiple myeloma: diagnosis and treatment. Mayo Clin Proc. 2016;91(1): 101-19. https://doi.org/10.1016/j.mayocp.2015.11. 007.

3. Rajkumar SV. Multiple myeloma: 2016 update on diagnosis, risk-stratification, and management. Am J Hematol. 2016;91(7):719-34. https://doi.org/10. 1002/ajh.24402.

4. Biran N, Jagannath S, Chari A. Risk stratification in multiple myeloma, part 1: characterization of highrisk disease. Clin Adv Hematol Oncol. 2013;11(8): 489-503.

5. Sanofi-Aventis U.S LLC. Sarclisa (isatuximab-irfc). Sanofi-Aventis U.S LLC. Bridgewater, NJ. 2020. http://products.sanofi.us/Sarclisa/sarclisa.pdf. Accessed 2 Mar 2020.

6. Sarclisa ${ }^{\circledR} 100 \mathrm{mg} / 500 \mathrm{mg}$ IV infusion approved for relapsed or refractory myeloma 2020 [press release]. Tokyo, Japan: Sanofi Japan. 2020. https://www. sanofi.co.jp/-/media/Project/One-Sanofi-Web/ Websites/Asia-Pacific/Sanofi-JP/Home/pressreleases/PDF/2020/200629-02.pdf?la=ja. Accessed 23 Jul 2020.

7. European Commission approves Sarclisa ${ }^{\circledR}$ (isatuximab) for adults with relapsed and refractory multiple myeloma [press release]. Paris, France: Sanofi France. 2020. https://www.sanofi.com/en/mediaroom/press-releases/2020/2020-06-02-12-47-38. Accessed 2 Jun 2020. 
8. FDA approves Sarclisa (isatuximab-ifrc) for patients with relapsed refractory multiple myeloma [press release]. 2020. https://www.sanofi.com/en/mediaroom/press-releases/2020/2020-03-02-19-51-16. Accessed 26 Oct 2020.

9. Sarclisa ${ }^{\circledR}$ (isatuximab) registration certificate in the Russian Federation. 2020. http://grls.rosminzdrav. ru/Grls_View_v2.aspx?routingGuid=c754e935ad28-4c1d-a643-0564811a2a00\&t. Accessed 27 Aug 2020 .

10. Attal M, Richardson PG, Rajkumar SV, et al. Isatuximab plus pomalidomide and low-dose dexamethasone versus pomalidomide and low-dose dexamethasone in patients with relapsed and refractory multiple myeloma (ICARIA-MM): a randomised, multicentre, open-label, phase 3 study. Lancet. 2019;394(10214):2096-107. https://doi. org/10.1016/S0140-6736(19)32556-5.

11. Dimopoulos MA, Oriol A, Nahi H, et al. Daratumumab, lenalidomide, and dexamethasone for multiple myeloma. N Engl J Med. 2016;375(14): 1319-31. https://doi.org/10.1056/NEJMoa1607751.

12. Lonial S, Dimopoulos M, Palumbo A, et al. Elotuzumab therapy for relapsed or refractory multiple myeloma. N Engl J Med. 2015;373(7):621-31. https://doi.org/10.1056/NEJMoa1505654.

13. Palumbo A, Chanan-Khan A, Weisel K, et al. Daratumumab, bortezomib, and dexamethasone for multiple myeloma. N Engl J Med. 2016;375(8): 754-66. https://doi.org/10.1056/NEJMoa1606038.

14. Dimopoulos M, Quach H, Mateos MV, et al. Carfilzomib, dexamethasone, and daratumumab versus carfilzomib and dexamethasone for patients with relapsed or refractory multiple myeloma (CANDOR): results from a randomised, multicentre, open-label, phase 3 study. Lancet. 2020;396(10245):186-97. https://doi.org/10.1016/ S0140-6736(20)30734-0.

15. Facon T, Kumar S, Plesner T, et al. Daratumumab plus lenalidomide and dexamethasone for untreated myeloma. N Engl J Med. 2019;380(22): 2104-15. https://doi.org/10.1056/NEJMoa1817249.

16. Moreau P, Attal M, Hulin C, et al. Bortezomib, thalidomide, and dexamethasone with or without daratumumab before and after autologous stem-cell transplantation for newly diagnosed multiple myeloma (CASSIOPEIA): a randomised, open-label, phase 3 study. Lancet. 2019;394(10192):29-38. https://doi.org/10.1016/S0140-6736(19)31240-1.

17. Mohammadi M, Cao Y, Glimelius I, Bottai M, Eloranta S, Smedby KE. The impact of comorbid disease history on all-cause and cancer-specific mortality in myeloid leukemia and myeloma-a Swedish population-based study. BMC Cancer. 2015;15:850. https://doi.org/10.1186/s12885-0151857-X.

18. Trakada G, Kastritis E, Gavriatopoulou M, et al. Pulmonary function abnormalities are common in patients with multiple myeloma and are independently associated with worse outcome. Ann Hematol. 2019;98(6):1427-34. https://doi.org/10. 1007/s00277-019-03641-X.

19. Janssen Biotech. Darzalex (daratumumab). Janssen Biotech. 2020. http://www.janssenlabels.com/ package-insert/product-monograph/prescribinginformation/DARZALEX-pi.pdf. Accessed 10 Nov 2020 .

20. Mikhael J, Ismaila N, Cheung MC, et al. Treatment of multiple myeloma: ASCO and CCO joint clinical practice guideline. J Clin Oncol. 2019;37(14): 1228-63. https://doi.org/10.1200/JCO.18.02096.

21. Song X, Cong Z, Wilson K. Real-world treatment patterns, comorbidities, and disease-related complications in patients with multiple myeloma in the United States. Curr Med Res Opin. 2016;32(1): 95-103. https://doi.org/10.1185/03007995.2015. 1105202.

22. Kleber M, Ihorst G, Gross B, et al. Validation of the Freiburg Comorbidity Index in 466 multiple myeloma patients and combination with the international staging system are highly predictive for outcome. Clin Lymphoma Myeloma Leuk. 2013;13(5):541-51. https://doi.org/10.1016/j.clml. 2013.03.013.

23. Vogelmeier CF, Criner GJ, Martinez FJ, et al. Global strategy for the diagnosis, management and prevention of chronic obstructive lung disease 2017 report: GOLD executive summary. Respirology. 2017;22(3):575-601. https://doi.org/10.1111/resp. 13012.

24. Mathers CD, Loncar D. Projections of global mortality and burden of disease from 2002 to 2030. PLoS Med. 2006;3(11):e442. https://doi.org/10. 1371/journal.pmed.0030442. 